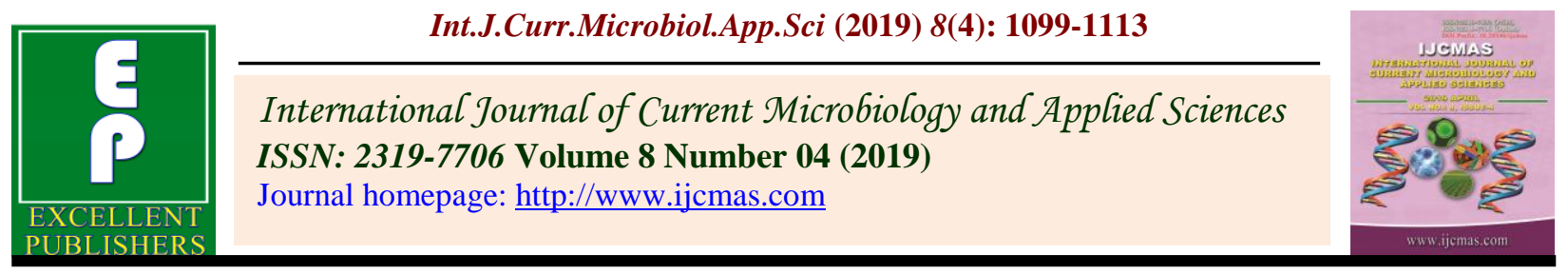

Original Research Article

https://doi.org/10.20546/ijcmas.2019.804.127

\title{
Characterization of Rainfall through Probability Distributions for Yadgir District in Karnataka, India
}

\author{
K. Pavan Kumar ${ }^{1}$, D.K. Swain ${ }^{2 *}$ and T.V. Vinay ${ }^{3}$ \\ ${ }^{1}$ Iffco-Tokio Insurance Ltd., ${ }^{2}$ School of Agriculture, ${ }^{3}$ Statistics, School Of Agriculture, GIET \\ University, Gunupur, Rayagada, Pin-765022, India \\ *Corresponding author
}

A B S T R A C T

\section{Keywords}

Weibull (3P,2P), GEV, Gamma (3P), Gumbel, Exponential, KS-test

Article Info

Accepted:

10 March 2019

Available Online: 10 April 2019
Different continuous probability distribution was used to characterize the annual rainfall of Yadgir district. The best fitted distributions for the annual rainfall data are Weibull (3P), GEV, Gamma (3P) and Gumbel based on KS-test. Nearly more than $70 \%$ of annual rainfall received from south monsoon (kharif season), the best fitted probability distribution for the period of south west monsoon are Weibull (2P), GEV, Gamma (3P), and Weibull (3P) based on KS-test. Among south west monsoon period September is highest receiving rainfall month, the best fitted continuous distributions are exponential, Gamma and Weibull (2P) based on KS-test.

\section{Introduction}

Rainfall is an important element of economic growth of an area or region, especially in a country like India, where a large number of people are occupied in agricultural activities. The amount of rainfall does not show an equal distribution, either in space or in time. It varies from heavy rain to scanty in different parts. It also has great regional and temporal variations in distribution. The characterization of rainfall distribution over different periods in a year is very important. Country's economy is highly dependent on agriculture. The rainfall distribution is often cited as one of the more important factors in cropping pattern in India. Systematic and instant attention should be given to know the distribution of rainfall in terms of seasons, months, weeks receiving rainfall.

Rainfall distribution pattern has considerable impact on agriculture sector of Asia Pacific region. The extreme events like floods, droughts frequently occur as a result of growth in population, increased urbanization and decreased intensity of rainfall and forest area. The different continuous probability are used in hydrological studies such as release water from water reservoirs from high level 
areas to low level areas. Probability distribution can also be used in defining distribution of drought, floods in different calendar years. If the distribution of rainfall pattern known well in advance a major socio economic damage can the managed.

\section{Materials and Methods}

Yadgir district which lies in HyderabadKarnataka (HK) is a new district and is 5 years old and it consists of 19 rain gauge stations out of which 16 are functional. The district lies in North Eastern Dry Zone of Karnataka (Zone -II) and enjoying semi-arid type of climate. The district has three taluks viz, Shahapur Shorapur and Yadgir

Distributions of rain gauge stations in different taluks are as follows.

Shahapur: Shahapur, Gogi, BI,Gudi, Wadgera, Dorana halli.

Shorapur: Shorapur, Kakkeeri, Kodekal, Narayanapur, Hunasagi, Kembhavi.

Yadgir: Yadgir, Saidapur, Gurmitkal, Balichakra, Konakal.

For the present study rainfall data of Yadgir district was collected for the newly created district from the district data from 2010 to 2013 and the data for the previous period (1980 - 2009) was collected from the data of Kalburgi district of which Yadgir was a part.

Daily rainfall data of sixteen functional raingauge station located in three taluks of Yadgir district was collected from AICRP on Agrometeorology of UAS Bengaluru and Directorate of Economic and Statistics for period (1980- 2013)

The table of Standard Meteorological Weeks was used to convert the daily rainfall data into weekly data. This standard table divided the entire year with 365 days into 52 Standard Meteorological Weeks out of which weeks pertaining to South West monsoon were considered for study i.e. $23^{\text {rd }}$ week to $39^{\text {th }}$ week (June to September).

Among the weather parameters, amount of daily rainfall $(\mathrm{mm})$ was considered to fit appropriate probability distributions. The probability distributions viz. normal, log normal, Gamma (1P, 2P, 3P), generalized extreme value (GEV), Weibull (1P, 2P, 3P), Gumbel and Pareto were used to evaluate the best fit probability distribution for rainfall.

\section{Description of parameters}

\section{Shape parameter}

A shape parameter is any parameter of a probability distribution that is neither a location parameter nor a scale parameter (nor a function of either or both of these only, such as a rate parameter). Shape parameters allow a distribution to take on a variety of shapes, depending on the value of the shape parameter. These distributions are particularly useful in modeling applications since they are flexible enough to model a variety of data sets. Examples of shape parameters are skewness and kurtosis.

\section{Scale parameter}

In probability theory and statistics, a scale parameter is a special kind of numerical parameter of a parametric family of probability distributions. The larger the scale parameter, the more spread out the distribution. The scale parameter of a distribution determines the scale of the distribution function. The scale is either estimated from the data or specified based on historical process knowledge. In general, a scale parameter stretches or squeezes a graph. The examples of scale parameters include variance and standard deviation. 


\section{Location parameter}

The location parameter determines the position of central tendency of the distribution along the $\mathrm{x}$-axis. The location is either estimated from the data or specified based on historical process knowledge. A location family is a set of probability distributions where $\mu$ is the location parameter. The location parameter defines the shift of the data. A positive location value shifts the distribution to the right, while a negative location value shifts the data distribution to the left. Examples of location parameters include the mean, median, and the mode.

The parameters estimation techniques used for continuous probability distribution are

i) Method of maximum likelihood.

ii) Method of moments.

\section{Method of maximum likelihood}

$\mathrm{X}_{1}, \mathrm{X}_{2}, \mathrm{X}_{3}, \ldots \mathrm{X}_{\mathrm{n}}$ have joint density denoted

$\mathrm{f}_{\Theta}\left(X_{1}, X_{2}, \ldots, X_{n}\right)=f\left(X_{1}, X_{2}, \ldots, X_{n} \mid \theta\right)$

Given observed values

$\mathrm{X}_{1}=\mathrm{x}_{1}, \mathrm{X}_{2}=\mathrm{x}_{2}, \ldots, \mathrm{X}_{\mathrm{n}}=\mathrm{x}_{1}$, the likelihood of $\theta$ is the function

$\operatorname{lik}(\theta)=f\left(X_{1}, X_{1}, \ldots, X_{1} \mid \theta\right)$ considered as a function of $\theta$.

If the distribution is discrete, $\mathrm{f}$ will be the frequency distribution function. In words: $\operatorname{lik}(\theta)=$ probability of observing the given data as a function of $\theta$.

Definition: The maximum likelihood estimate (MLE) of $\theta$ is that value of $\theta$ that maximises $\operatorname{lik}(\theta)$ : it is the value that makes the observed data the "most probable".

If the $X_{1}$ are iid, then the likelihood simplifies to

$\operatorname{lik}(\theta)=\prod_{i=1}^{n} f\left(x_{i} / \theta\right)$

Rather than maximising this product which can be quite tedious, we often use the fact that the logarithm is an increasing function so it will be equivalent to maximise the $\log$ likelihood:

$l(\theta)=\sum_{i=1}^{n} \log \left(f\left(x_{i} / \theta\right)\right.$

\section{Properties of MLE}

Any consistent solution of the likelihood equation provides a maximum of the likelihood with probability tending to unity as the sample size (n) tends to infinity.

A consistent solution of the likelihood equation is asymptotically normally distributed about the true $\theta_{0}$ thus $\hat{\theta}$ is asymptotically $N\left(\theta_{0}, \frac{1}{I\left(\theta_{0}\right)}\right)$ as $\mathrm{n}$ tends to $\infty$

IF MLE exists it is the most efficient in the class of such estimators.

If a sufficient estimator exists, it is a function of the maximum likelihood estimators.

\section{Method of Moments}

The method of moment is probably the oldest method for constructing an estimator, this method of estimation discovered by Karl Pearson, an English mathematical statistician, in the late 1800 's

Suppose a random variable $\mathrm{X}$ has density $\mathrm{f}(\mathrm{x} \mid \theta)$, and this should be understood as point mass function when the random variable is discrete otherwise density function.

The k-th theoretical moment of this random variable is defined as

$$
\begin{gathered}
\mu_{x}=E\left(X^{k}\right)=\int x^{k} f(x / \theta) d x \\
\text { or } \mu_{x}=E\left(X^{k}\right)=\sum x^{k} f(x / \theta)
\end{gathered}
$$


If $\mathrm{X}_{1}, \cdots, \mathrm{X}_{\mathrm{n}}$ are i.i.d. random variables from that distribution, the k-th sample moment is defined as $m_{x}=\frac{1}{n} \sum_{i=1}^{n} X_{i}^{k}$

thus mk can be viewed as an estimator for $\mu \mathrm{k}$. From the law of large number, we have $\mathrm{mk} \rightarrow \mu \mathrm{k}$ in probability as $\mathrm{n} \rightarrow \infty$.

\section{Properties of Method of Moments}

Let $\mathrm{X}_{1} \mathrm{X}_{1}, \mathrm{X}_{2}, \mathrm{X}_{3} \ldots, \mathrm{X}_{\mathrm{n}}$ ba random sample of size $\mathrm{n}$ from a population with p.d.f $f(x, \theta)$. Then $\mathrm{X}_{\mathrm{i}}$, $(\mathrm{i}=1,2, \ldots, \mathrm{n})$ are iid $X_{i}^{r}(\mathrm{I}=1,2, \ldots, \mathrm{n})$ are iid Hence if $E(X)$ exists then by by W.L.L.N., we get

$\frac{1}{n} \sum_{i=1}^{n} x_{i}^{r} \rightarrow E(X) \Rightarrow m^{\prime} \rightarrow \mu_{r} . \quad$ Hence the sample moments are consistent estimators of the corresponding population moments are asymptotically normal but not in general, efficient.

Generally, the method of moments yields less efficient estimators than those obtained from MLE, the estimators obtained by the method of moments are identically with those given by the method of maximum likelihood if the probability mass function or probability density function is of the form

$$
f(x, \theta)=\exp \left(b_{0}+b_{1} x+b_{2} x^{2}+, \ldots,\right)
$$

Where b's are independent of $\mathrm{x}$ but may depend on $\theta=\left(\theta_{1}, \theta_{2}, \ldots, \theta_{n}\right)$ The estimates obtained by the method are asymptotically normally distributed, but not in generally.

\section{Testing for goodness of fit}

The goodness of fit test measures the discrepancy between observed values and the expected values. Kolmogorov- Smirnov test was used to test for the goodness of fit.

In the present investigation, the goodness of fit test was conducted at 5 per cent level of significance. It was applied for testing the following hypothesis:

$\mathrm{H}_{0}$ : The maximum daily rainfall data follows a specified distribution.

$\mathrm{H}_{1}$ : The maximum daily rainfall data does not follow a specified distribution.

\section{Kolmogorov-Smirnov test (K-S test)}

This test was used to decide whether a sample comes from a hypothesized continuous PDF.

The KS test compares the cumulative distribution functions of the theoretical distribution the distribution described by the estimated shape and scale parameters with the observed values and returns the maximum difference between these two cumulative distributions.

This maximum difference in cumulative distribution functions is frequently referred to as the KS-statistic.

It is based on the empirical distribution function i.e., on the largest vertical difference between the theoretical and empirical cumulative distribution functions, which is given as:

$$
D=\max _{1 \leq i \leq n}\left(F\left(X_{i}\right)-\frac{i-1}{n}, \frac{i}{n}-F\left(X_{i}\right)\right)
$$

Where, $\mathrm{X}_{\mathrm{i}}=$ Random Value, $\mathrm{i}=1,2, \ldots$,

n. $C D F=F_{n}(X)=\frac{1}{n}$

[Number of observations $\leq \mathrm{x}]$. 


\section{Results and Discussion}

The probability distributions are used to evaluate the best fit for rainfall data for different period under study, distribution tried are normal, log normal, Gamma (1P, 2P, 3P), Generalized Extreme Value (GEV), Weibull (1P, 2P, 3P), Gumbel and Pareto. The goodness of fit for different probability distributions was tested using KolmogorovSmirnov test (KS test). The test statistic D along with the p-values for each data set was computed for 11 probability distributions. Table 1 presents the different distribution fitted for different period and periods studied as annual, seasonal, monthly, and weekly, have been briefly mentioned (Fig. 1-12).

\section{Annual}

For annual data of the district different distribution are fitted and best fitted distribution are identified based on KS test. The fitted distribution are Weibull (3P), GEV, Gamma (3P) and Gumbel and their test statistic values are $0.1317,0.1343,0.1363$ and 0.1370 respectively. Based on KS test lowest test statistic was observed for Weibull (3P) distribution which is the best fit and estimated values for shape, scale and location parameters are 1.3755, 903.51, and 303.63 respectively which are presented in Table 1.1 and Table 1.2.

\section{Season}

The distribution fitted for seasonal rainfall of the district is based on 34 years and distribution tried are tried Weibull (2P), GEV, Gamma (3P), and Weibull (3P) and their statistic values are $0.0853,0.0896,0.0932$ and 0.0974 respectively. Best fitted distribution was Weibull (2P) with estimated shape and scale parameter of 4.4974 and 34.028 respectively and is presented in Table 1.1 and Table 1.2.

\section{June}

34 years rainfall data of June month were fitted with the following probability distributions viz., Weibull (2P), GEV, Gamma (3P) and Weibull (3P) and KS statistic values are $0.0816,0.0857,0.0891$, 0.0928 and 0.1228 respectively. The best fitted distribution with lowest test statistic was Weibull (2P) with estimated shape and scale parameter value 3.5806 and 528.03 respectively.

\section{July}

Probability distributions fitted for rainfall data of July month of study period are lognormal, Weibull (2P), GEV, Gamma, Gamma (3P), and their KS test statistic values are 0.0967, $0.1134, \quad 0.1170, \quad 0.1201, \quad$ and 0.1228 respectively. The best fitted distribution was lognormal and estimated scale and location parameter values are 0.4929 and 4.7357 respectively as presented in Table 1.1 and Table 1.2.

\section{August}

For August month rainfall probability distributions fitted are GEV, Weibull (2P), Weibull (3P), Gamma (3P), Gamma and test statistic values are $0.0601,0.0650,0.0778$, 0.0782 and 0.0793 respectively. The smallest test statistic value for GEV and is the best fit with estimated parameters values for shape, scale and location are 0.0651, 63.112, and 110.94 respectively as showed in Table 1.1 and Table 1.2.

\section{September}

The lowest KS statistic value is obtained for Gamma distribution and it is the best fit with estimated shape and scale parameter are 34.028 and 4.4974 respectively which is shown in Table 1.1 and Table 1.2. 
Table.1.1 Description of various probability distribution functions

\begin{tabular}{|c|c|c|}
\hline Distribution & Probability density function & Range \\
\hline Gamma (1P) & $f(x)=\frac{1}{\Gamma(k)} x^{k-1} \exp (-x)$ & $\begin{array}{l}0<x<\infty \\
\mathrm{k}>0\end{array}$ \\
\hline Gamma (2P) & $f(x)=\frac{1}{\Gamma(k) \beta^{k}} x^{k-1} e^{--\frac{x}{\beta}}$ & $\begin{array}{l}0<x<\infty \\
\beta>0, \mathrm{k}>0\end{array}$ \\
\hline Gamma (3P) & $f(x)=\frac{(x-\mu)^{k-1}}{\beta^{k} \Gamma(k)} \exp \left(-\frac{(x-\mu)}{\beta}\right)$ & $\begin{array}{l}\alpha>0, \beta>0 \\
\gamma>0\end{array}$ \\
\hline GEV & $f(x)= \begin{cases}\frac{1}{\beta} \exp \left[-(1+k z)^{\frac{-1}{k}}\right](1+k z)^{-1-1 / k} & k \neq 0 \\
\frac{1}{\beta} \exp [-z-\exp (-z)] & k=0\end{cases}$ & $\begin{array}{l}1+k z>0 \\
\text { for } \mathrm{k} \neq 0 \\
-\infty<\mathrm{x}<+\infty \\
\text { for } \mathrm{k}=0 \\
\text { where, } z=\frac{(x-\mu)}{\beta}\end{array}$ \\
\hline Normal & $f(x)=\frac{1}{\sigma \sqrt{2 \pi}} \exp \left[-\frac{1}{2} \frac{(x-\mu)^{2}}{\sigma^{2}}\right]$ & $\begin{array}{l}-\infty<\mathrm{x}<+\infty \\
-\infty<\mu<+\infty \\
\sigma>0\end{array}$ \\
\hline Log- normal & $f(x)=\frac{1}{x \sigma \sqrt{2 \pi}} \exp \left[-\left(\frac{(\ln (x)-\mu)^{2}}{2 \sigma^{2}}\right)\right]$ & $\mathrm{x}>0 . \sigma>0$ \\
\hline Gumbel & $\begin{array}{l}f(x)=\frac{1}{\beta} \exp -\left(z+e^{-z}\right) \\
\text { Where, } z=\frac{x-\mu}{\beta}\end{array}$ & $\begin{array}{l}\beta>0 \\
-\infty<x<+\infty\end{array}$ \\
\hline Pareto & $f(x)=\frac{k \beta^{k}}{\beta^{k+1}}$ & $\begin{array}{l}1 \leq x \leq+\infty \\
k, \beta>0 \\
x \geq 1\end{array}$ \\
\hline Weibull (1P) & $f(x)=k x^{k-1} \exp \left(-x^{k}\right)$ & $\begin{array}{l}x>0 \\
\beta>0\end{array}$ \\
\hline Weibull (2P) & $f(x)=\frac{k}{\beta}\left(\frac{x}{\beta}\right)^{k-1} \exp -\left(\frac{x}{\beta}\right)^{k}$ & $\begin{array}{l}0 \leq \mathrm{x}<+\infty \\
k, \beta,>0\end{array}$ \\
\hline Weibull (3P) & $f(x)=\frac{k}{\beta}\left(\frac{x-\mu}{\beta}\right)^{k-1} \exp -\left(\frac{x-\mu}{\beta}\right)^{k}$ & \\
\hline
\end{tabular}

$\mathrm{k}=$ Shape parameter, $\beta=$ Scale parameter, $\mu=$ location parameter, $\sigma=$ standard deviation 
Table.1.2 KS test statistic for Probability distributions in different periods

\begin{tabular}{|c|c|c|c|c|}
\hline \multirow[t]{2}{*}{ Study Period } & \multirow{2}{*}{ Range } & \multicolumn{3}{|c|}{ Kolmogorov Smirnov } \\
\hline & & Distribution & Statistic & p-value \\
\hline \multirow[t]{4}{*}{ Annual } & \multirow[t]{4}{*}{ 1Jan-31 Dec } & Weibull (3P) & 0.1317 & 0.5346 \\
\hline & & Gen. Extreme Value & 0.1343 & 0.5096 \\
\hline & & Gamma (3P) & 0.1363 & 0.4907 \\
\hline & & Gumbel & 0.1370 & 0.4844 \\
\hline \multirow[t]{4}{*}{ Seasonal } & \multirow[t]{4}{*}{1 June- 30Sep } & Weibull & 0.0853 & 0.9475 \\
\hline & & Gen. Extreme Value & 0.0896 & 0.9250 \\
\hline & & Gamma (3P) & 0.0932 & 0.9022 \\
\hline & & Weibull (3P) & 0.0974 & 0.8727 \\
\hline \multirow[t]{5}{*}{ June } & \multirow[t]{5}{*}{1 June-30 June } & Weibull (2P) & 0.0816 & 0.9677 \\
\hline & & Gen. Extreme Value & 0.0857 & 0.9515 \\
\hline & & Gamma (3P) & 0.0891 & 0.9347 \\
\hline & & Weibull (3P) & 0.0928 & 0.9135 \\
\hline & & Gamma & 0.1007 & 0.8577 \\
\hline \multirow[t]{5}{*}{ July } & \multirow[t]{5}{*}{1 July-31 July } & Lognormal & 0.0967 & 0.8779 \\
\hline & & Weibull & 0.1134 & 0.7319 \\
\hline & & Gen. Extreme Value & 0.1170 & 0.6964 \\
\hline & & Gamma & 0.1201 & 0.6661 \\
\hline & & Gamma (3P) & 0.1228 & 0.6389 \\
\hline \multirow[t]{5}{*}{ August } & \multirow{5}{*}{1 Aug-31 Aug } & Gen. Extreme Value & 0.0601 & 0.999 \\
\hline & & Weibull & 0.0650 & 0.9968 \\
\hline & & Weibull (3P) & 0.0778 & 0.9761 \\
\hline & & Gamma (3P) & 0.0782 & 0.9749 \\
\hline & & Gamma & 0.0793 & 0.9715 \\
\hline \multirow[t]{6}{*}{ September } & \multirow[t]{6}{*}{1 Sep-30 Sep } & Gamma & 0.0958 & 0.8843 \\
\hline & & Weibull & 0.0973 & 0.8731 \\
\hline & & Gen. Extreme Value & 0.1089 & 0.7744 \\
\hline & & Weibull (3P) & 0.1126 & 0.7393 \\
\hline & & Gamma (3P) & 0.1157 & 0.7096 \\
\hline & & Lognormal & 0.1204 & 0.6633 \\
\hline \multirow[t]{2}{*}{$23^{\text {rd }}$ SMW } & \multirow[t]{2}{*}{4 June-10 June } & Gen. Extreme Value & 0.10344 & 0.8238 \\
\hline & & Gamma & 0.1260 & 0.6076 \\
\hline \multirow[t]{2}{*}{$24^{\text {th }}$ SMW } & \multirow{2}{*}{11 June-17June } & Weibull (3P) & 0.0903 & 0.92069 \\
\hline & & Gamma & 0.0978 & 0.8691 \\
\hline \multirow[t]{2}{*}{$25^{\text {th }}$ SMW } & \multirow[t]{2}{*}{18 June-24 June } & Gamma (3P) & 0.0886 & 0.9303 \\
\hline & & Weibull & 0.0942 & 0.8954 \\
\hline \multirow[t]{2}{*}{$26^{\text {th }}$ SMW } & \multirow[t]{2}{*}{25 June-1 July } & Lognormal & 0.0658 & 0.9962 \\
\hline & & Gen. Extreme Value & 0.0695 & 0.9927 \\
\hline \multirow[t]{2}{*}{$27^{\text {th }}$ SMW } & 2 July-8 July & Gen. Extreme Value & 0.1433 & 0.4457 \\
\hline & & Lognormal & 0.1600 & 0.3140 \\
\hline $28^{\text {th }}$ SMW & 9 July-15 July & Gen. Extreme Value & 0.0890 & 0.9283 \\
\hline & & Gamma & 0.1188 & 0.6789 \\
\hline $29^{\text {th }}$ SMW & 16 July-22 July & Normal & 0.1323 & 0.5468 \\
\hline & & Gumbel & 0.1410 & 0.4660 \\
\hline
\end{tabular}


Table.2 Parameter estimation of the best fitted distribution

\begin{tabular}{|c|c|c|c|c|c|}
\hline \multirow[t]{2}{*}{ Study Period } & \multirow[t]{2}{*}{ Range } & \multirow[t]{2}{*}{ Best fit } & \multicolumn{3}{|c|}{ Parameters } \\
\hline & & & $\begin{array}{c}\text { Shape } \\
\text { parameter }\end{array}$ & $\begin{array}{c}\text { Scale } \\
\text { parameter }\end{array}$ & $\begin{array}{l}\text { Location } \\
\text { parameter }\end{array}$ \\
\hline Annual & 1Jan-31 Dec & Weibull (3P) & 1.3755 & 903.51 & 303.63 \\
\hline Seasonal & 1 June- 28 Oct & Weibull (2P) & 4.4974 & 34.028 & - \\
\hline June & 1 June-30 June & Weibull (2P) & 3.5806 & 528.03 & \\
\hline July & 1 July-31 July & lognormal & - & 0.4929 & 4.7357 \\
\hline August & 1 Aug-31 Aug & GEV & 0.0651 & 63.112 & 110.94 \\
\hline September & $1 \mathrm{Sep}-30 \mathrm{Sep}$ & Gamma (2P) & 34.028 & 4.4974 & \\
\hline $23^{\text {rd }}$ SMW & 4 June-10 June & GEV & 0.317 & 6.7242 & 4.8515 \\
\hline $24^{\text {th }}$ SMW & 11 June-17 June & Weibull (3P) & 0.9112 & 19.742 & 0.0285 \\
\hline $25^{\text {th }}$ SMW & 18 June-24 June & Gamma (3P) & 0.7203 & 36.5 & 0.1714 \\
\hline $26^{\text {th }}$ SMW & 25 June-1 July & Lognormal & & 1.3261 & 2.2771 \\
\hline $27^{\text {th }}$ SMW & 2 July-8 July & GEV & 0.5542 & 11.686 & 10.68 \\
\hline $28^{\text {th }}$ SMW & 9 July-15 July & GEV & 0.277 & 12.934 & 11.381 \\
\hline $29^{\text {th }}$ SMW & 16 July-22 July & Normal & & 22.271 & 24.913 \\
\hline $3^{\text {th }}$ SMW & 23 July-29 July & Gamma (3P) & 0.64182 & 46.449 & 0.9714 \\
\hline $31^{\text {st }}$ SMW & 30 July-5 Aug & Weibull (3P) & 1.2548 & 43.933 & -0.2397 \\
\hline 32 $2^{\text {nd }}$ SMW & 6 Aug-12 Aug & Gamma (2P) & 1.2222 & 26.492 & \\
\hline $3^{\text {rd }}$ SMW & 13 Aug-19 Aug & Gamma (3P) & 0.73813 & 48.548 & 0.4285 \\
\hline $34^{\text {th }}$ SMW & 20 Aug-26 Aug & Gamma (3P) & 0.7829 & 38.988 & 0.6 \\
\hline $35^{\text {th }}$ SMW & 27 Aug-2 Sep & Lognormal & & 1.3874 & 2.814 \\
\hline $36^{\text {th }}$ SMW & 3 Sep-9 Sep & Lognormal & & 1.4276 & 2.7418 \\
\hline $37^{\text {th }}$ SMW & 10 Sep-16 Sep & GEV & 0.0597 & 24.168 & 21.341 \\
\hline $38^{\text {th }}$ SMW & 17 Sep-23 Sep & Gamma (2P) & 0.8147 & 45.402 & \\
\hline $39^{\text {th }}$ SMW & 24 Sep-30 Sep & Gamma (2P) & 1.1027 & 43.298 & \\
\hline
\end{tabular}

Fig.1 Weibull (3P) distribution for annual rainfall data

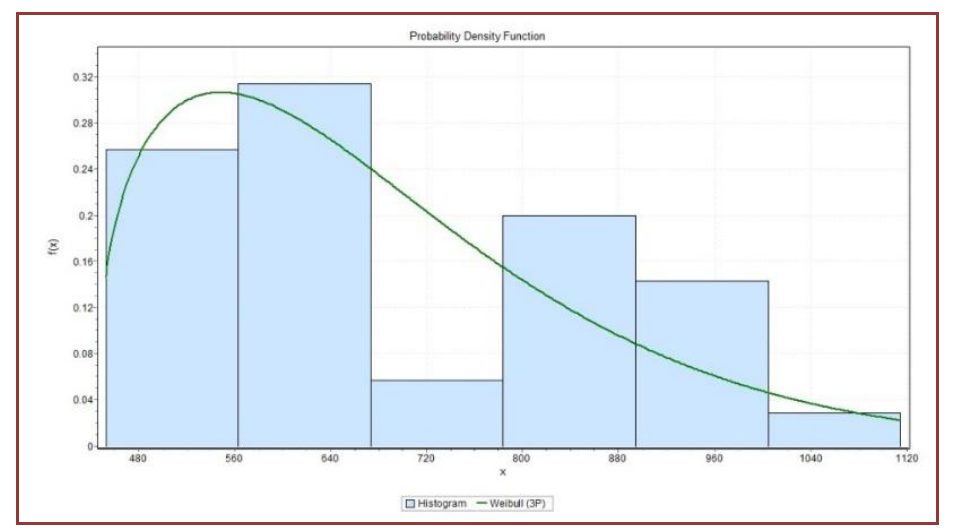


Fig.2 GEV distribution for annual rainfall data

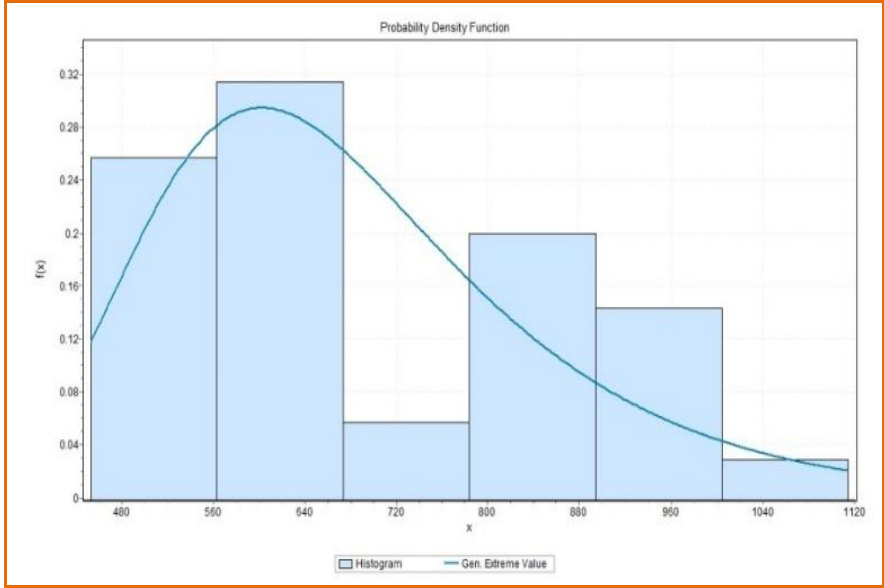

Fig.3 Gumbel distribution for annual rainfall data

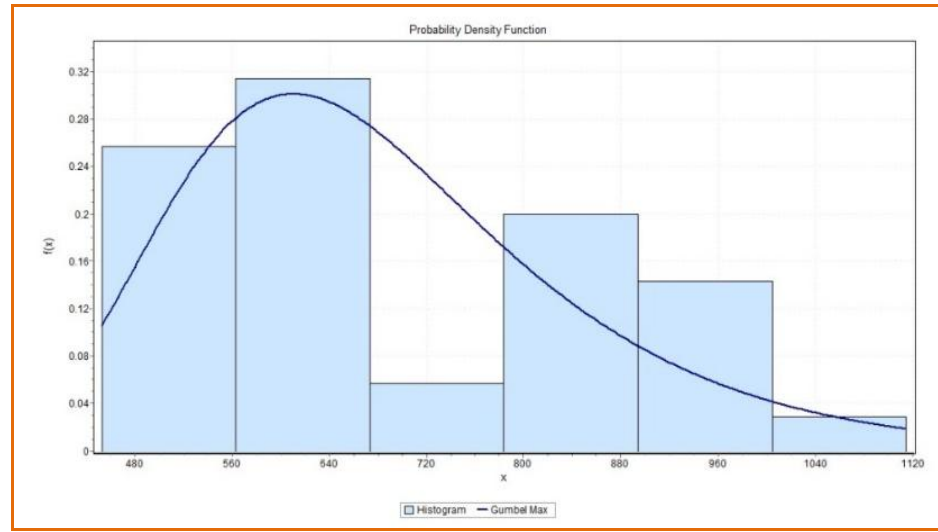

Fig.4 Gamma (3P) distribution for annual rainfall data

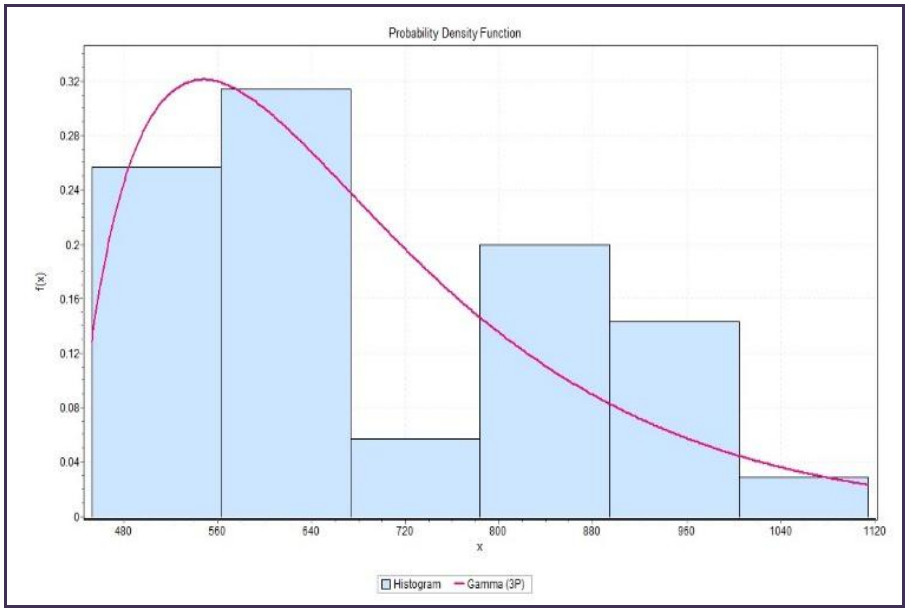


Fig.5 Weibull (2P) distribution for seasonal rainfall data

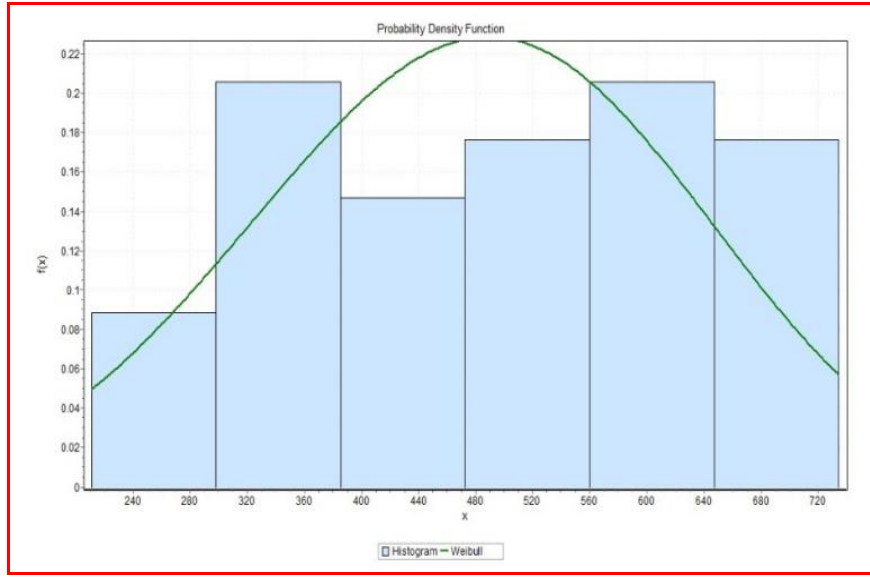

Fig.6 GEV distribution for seasonal rainfall data

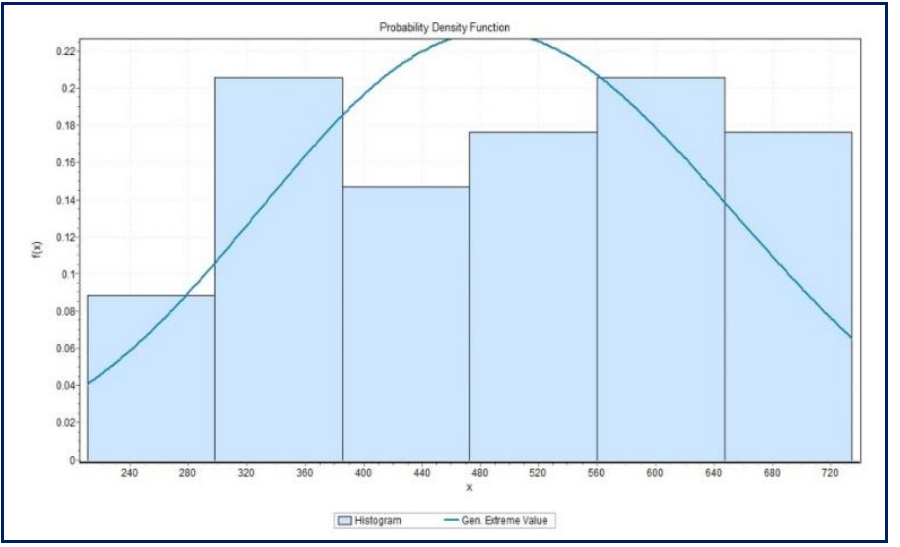

Fig.7 Gamma (3P) distribution for seasonal rainfall data

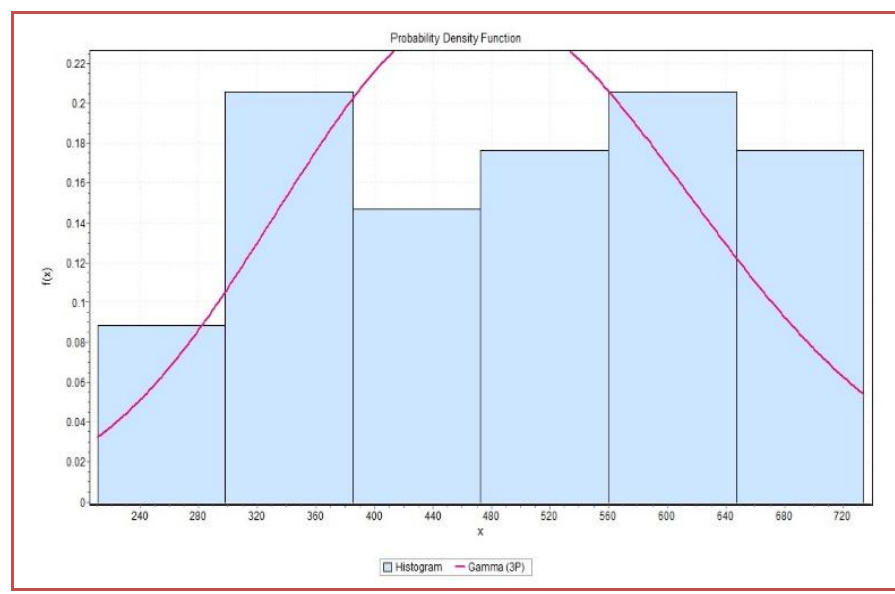


Fig.8 Weibull (3P) distribution for seasonal rainfall data

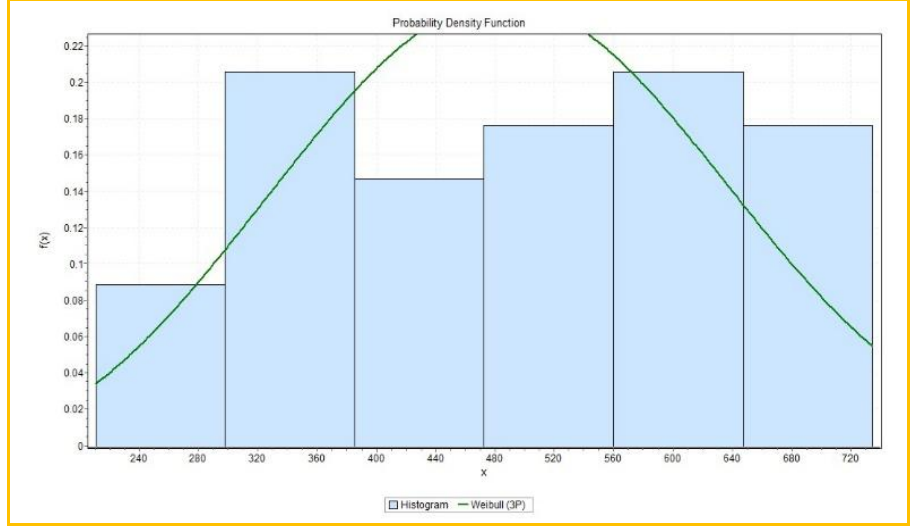

Fig.9 Gamma distribution for September month rainfall data

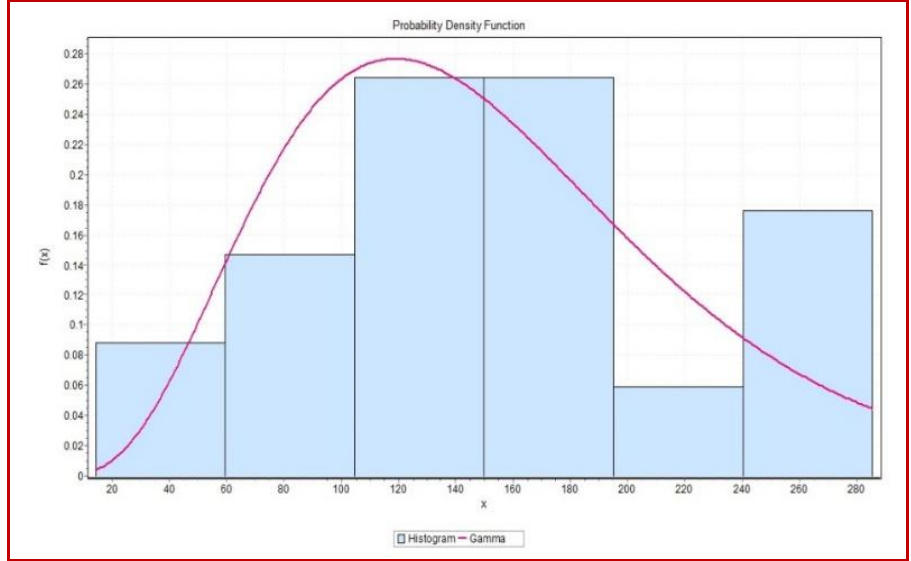

Fig.10 GEV distribution for September month rainfall data

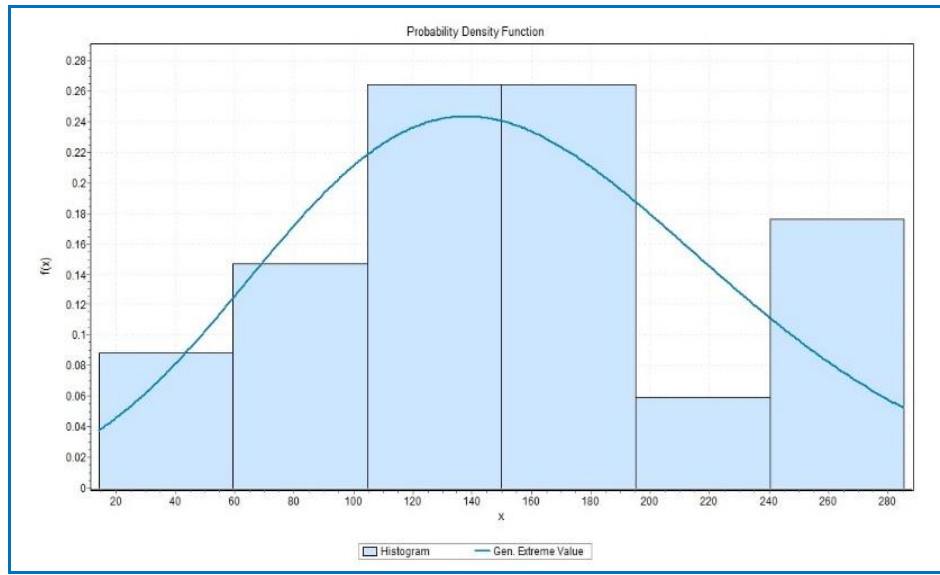


Fig.11 Weibull distribution for September month rainfall data

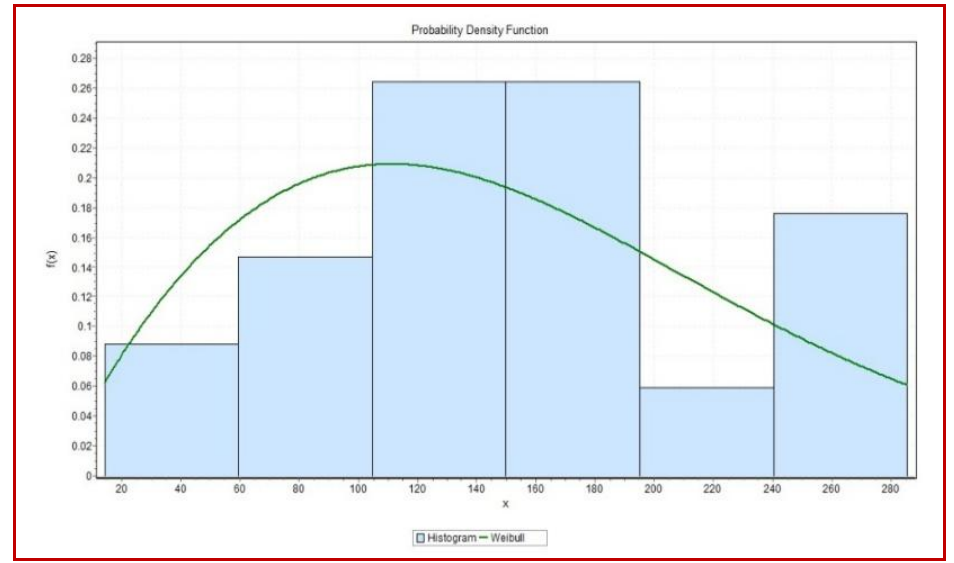

Fig.12 lognormal distribution for September month rainfall data

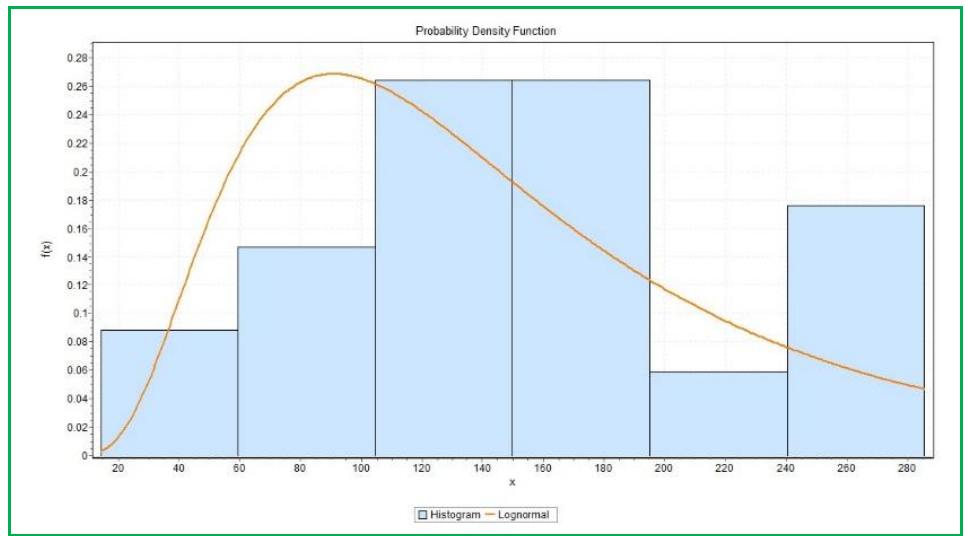

In conclusion, different continuous probability distributions were used to know the distribution pattern of rainfall in study area and the distributions used are gamma (1P.2P, 3P), Weibull (1P, 2P, 3P), general extreme value (GEV), Pareto, lognormal, exponential and Gumbel distribution. Kolmogorov- Smirnov test (KS test) probabilities were obtained for the distribution fitted and these probabilities were used to identify the distribution that fits best.

For annual rainfall data of the district tried with above mention distribution, the fitted distributions based on KS-test are Weibull (3P), GEV and Gumbel. Figure 1, 2 and 3 show the three distribution viz., Weibull (3P), GEV and Gumbel which have fitted well for annual rainfall. Of these three, Weibull (3P) is the best fit since its value for goodness of fit is the best. All these distribution have a fairly long tail on the right.

For seasonal rainfall the four distributions which have fitted well are Weibull (2P), GEV, gamma (3P). These four distribution have been shown in Figure 5, 6, 7 and 8 respectively. September month receives maximum rainfall through South West monsoon. Of the distributions tried, gamma, GEV, Weibull and lognormal have fitted well for the monthly data of September. Gamma distribution is the best fit among good fits on the same line estimates of standard meteorological weekly of south west monsoon are present. 


\section{References}

BHAVANA, C. P, MUNIRAJAPPA, R, SURENDRA, H,S. AND SANTOSHA RATHOD., 2012, Modeling of daily rainfall using gamma probability distribution, Env and Eco.,30(3)::884887

BHUSHANA BABU, V., 2015, Probability Models for spatial and temporal distributions of rainfall in Haryana, Ph.D ThesisChaudhary Charan Singh Haryana agricultural university, Hissar.

BUISHAND, T. A., 1982, Some methods for testing the homogeneity of rainfall records. J. Hydrol., 58:11-27

DIKKO, H. G., DAVID, I. J., AND BAKARI, H.R., 2013, Modeling the distribution of rainfall intensity using quarterly data. J. Maths. 9(1): 11-16

GREGORY, J, HUSAK., JOEL MICHAELSEN. AND CHRIS FUNK., 2007, Use of the gamma distribution to represent monthly rainfall in Africa for drought monitoring Int. J. Climt. 10:5698.

HANUMANTHAPPA, RAMDURG., SRINIVASA, REDDYG. V., KRISHNAMURTHY, D., MAHESHWARA BABU, D., AND NEMICHANDRAPPA, M., 2015, Weekly rainfall variability and probability analysis for resource planning at Hadagali, Karnataka, Int. J. Agric. Eng., 8(2):255-260.

HEIKKI TUOMENVIRTA., 2002, Homogeneity testing and adjustment of climatic time series in finland. Geophysica., 38:15-41.

HO MING KANG., AND FADHILAH YUSOF., 2012, Homogeneity tests on daily rainfall series. Int. J. Cont. Math. Sci., Vol. 7(1): $9-22$

ISHAPPA MUNIYAPPA RATHOD.ANDARUCHAMY, S., 2010, Rainfall trends and pattern of
Kongu Upland, Tamil Nadu, India, using GIS Techniques Int. J. En. Sci, 1(2):109-122.

IYENGAR, R.N., 1991, Application of Principal Component Analysis to understand variability of rainfall. Proc. Indian Acad. Sci. (Earth Planet Sci.)., 100(2): 105-126.

JAKUB LANGHAMMER., AND JANA BERNSTEINOVA., 2015 Runoff response to climate warming and forest disturbance in a mid-mountain basin. Water 7:3320-3342.

JAMALUDIN SUHAILA., KONG CHINGYEE., YUSOF FADHILAH., AND FOO HUI-MEAN., 2011, Introducing the mixed distributions in fitting rainfall data. J. Modern. Hyd., 1(2): 11-22.

JOBINTHOMAS, PRASANNAKUMAR, V., 2016. Temporal analysis of rainfall (1871-2012) and drought characteristics over a tropical monsoon-dominated State (Kerala) of India. J. modern. Hyd., 534: 266-280.

KAPIL G., AND LOKANANDHAM, B., 2008, Characterization of Spatial and Temporal distribution of monsoon rainfall in Mumbai, India, $11^{\text {th }}$ Int. Conf Urb Drig, Edinburgh, Scotland, UK, 31 August - 5 September, p 1-10.

KHALIQA, M, N, AND OUARDA T, B, M, J, 2007 Short communication on the critical values of the standard normal homogeneity test (SNHT). Int. J. Clim., 27: 681-687.

KRISHNAMURTHY， K. N., GOWDA, D.M., AND VASANTHKUMAR, T., 2015 use of some probability distributions in rainfall analysis Ind. Str. Res J. 5 (6):1-8

KRISHNAMURTHY.,K.N., BHOOMIKA., RAJ, R., GOWDA., D. M., RAJEGOWDA., B. M. Fitting statistical distrubtions for maximum daily rainfall at gkvk station. Int. J Pure and Apl Res. Eng. Tech, 3(12): 64-74. 
KUMAR, PRAMOD, MEENA., DEEPAK KHARE., RITURAJ SHUKLA. AND MISHRA, P. K., 2015, Long term trend analysis of mega cities in Northern India using rainfall data Ind. J. Sci. Tech, 8(3):247-253.

LALA I., RAY, P.,.BORA P. K., RAM V., SINGH A. K., SINGH N. J., SINGH R., FEROZE S. M., 2013, Estimation of annual maximum rainfall for Central Meghalaya. Ind. J. Hill Farg, 26(1): 4751.

MAHALINGAM, B., RAMU., BHARATH AND JAYASHREE., 2014, Rainfall variability in space and time, A case study of Mysore district, Karnataka, India. Currt. Trd. Tech. Sci., 3(3): 205209

MANI, SABARISH,R., NARASIMHAN, R., CHANDHRU, A. R., SURIBABU, C, R.,SUDHARSAN,J.ANDNITHIYANA NTHAM,S., 2015, Probability analysis for consecutive-day maximum rainfall for Tiruchirapalli City, Appl. Water Sci.8:1-10.

MANIKANDAN, M. AND TAMILMANI, D., 2012, Statistical analysis of spatial pattern of rainfall trends in Parambikualam Aliyar Sub basin, Tamil Nadu. J. Ind. Water. Res. Socty., 32(1): 40-49.

MARKAND OZA. AND. KISHTAWAL, C.M., 2014., Spatial analysis of Indian summer monsoon rainfall. J. Geo. $8(1): 10-15$

MAYOORAN, T., AND LAHEETHARAN, A., 2014, The statistical distribution of annual maximum rainfall in colombo district Sri Lankan J. Appl. Sta. 1:15-2.

MOROZOVA, A, L, AND VALENTE, M., A, 2012 Homogenization of Portuguese long-term temperature data series, Earth Syst. Sci. Data, 4:187-213.

NANDEESHA, AND RAMU., 2015, Assessment of rainfall patterns and meteorological drought in Northern dry agro climatic zone of Karnataka. Int $J$. Compt. Sci. Info. Tech. 3: 532-539.

OSENI, B. AZEEZ AND FEMI, J. AYOOLA., 2012, Fitting the statistical distribution for daily rainfall in Ibadan, based on chi square and KolmogorovSmirnov goodness of fit tests. European. J. Bus. Mang. 4(17): 62-70.

PANDA, R,K., NAIK, B.S., GORE, K.P., MISHRA， P.K., JAKHAR，P. AND GOWDA. H., 2009., Use of probability distribution models in rainfall analysis for post-monsoon crop planning in Eastern ghat Region of Orissa Ind. J. Dr. Agri. Res. Devt. 24(1): 75-80.

PATEL, M., ISH, N. R., AND SHETE, F., ISH, D, T., 2008, Probability distribution analysis of consecutive days rainfall data for Sabarkantha district of North Gujarat region, India. Ind. Socty. Hyd. J. Eng. 14(3): 43-55.

PETTITT, A.N., (1979 A Non-parametric approach to the change-point detection. Appl. Stat., 28: 126-135.

RAJNEESH, AND ANIL BHARDWAJ., 2015, Probability analysis of return period of daily maximum rainfall in annual data set of Ludhiana, Punjab Indian J. Agric. Res. 49 (2): 160-164.

RAMARAJ, A. P., KOKILAVANI, S., MANIKANDAN, N., ARTHIRANI, B. AND RAJALAKSHMI, D., 2015., Rainfall stability and drought evaluation (Using SPI) Over Southern Zone of Tamil Nadu., Curt World Env., 10: 928933.

RASMITA KUMARI SAHU. AND DEEPAK KHARE., 2015, spatial and temporal analysis of rainfall trend for 30 districts of a coastal state (odisha) of india. Int. J. Glogy, Erth \& Env. Sci.5 (1):23-32

RAVISHAH, V. L, MANEKAR, R. A, CHRISTIAN. AND N. J., 2013., MISTRY Estimation of reconnaissance drought index (RDI) for Bhavnagar 
District, Gujarat. India Int. J. Env. Che, Eco, Geog and Geoph. l Eng. 7: 2:7.

ROMAN., U,C., POREY P, D., PATEL P,L, AND VIVEKANANDAN, N., 2012, Assessing adequacy of probability distributional model for estimation of design storm. J. Eng. Sci. 1(1):19-25.

SANTHOSH, F. BABAR AND RAMESH, H., 2013, Analysis of south-west monsoon rainfall trend using statistical techniques over Nethravathi basin. Int. J Advancer Tech. Civil Eng. 2(1): 130136.

SAROJINI ACHARY., AND GANGADHAR BHAT, H., 2013, Spatial and temporal variation of rainfall in the selected stretches of southern Karnataka coast, Proceedings of Global Engineering, Science and Technology Conference 3-4 October 2013, Bay View Hotel, Singapore.
SEN, Z AND ELJADID,A.G., 1999, Rainfall distribution function for Libya and rainfall prediction, Journal of Hydrological Science, 44(5):665-680

SHARAD, K. JAIN AND VIJAY KUMAR, 2012, Trend analysis of rainfall and temperature data for India. Current Science. 102(1): 37-49.

SINGH, S. P., HUNDAL, S. S. AND AUJLA, M.S., 2004, Dry and wet spell sequence for crop planning at Bathinda, Punjab-A Markov chain approach. J. Agro. 6:242246

STEPHEN BUNMI OGUNGBENRO., AND TOBI ENIOLU MORAKINYO., 2014 Rainfall distribution and change detection across climatic zones in Nigeria. Weath and Clim. Extr. 5:1-6.

SUBBAIAH, R. AND SAHU, D. D., 2002 Stochastic model for weekly rainfall of Junagadh. J. Agr. 6: 242-246.

\section{How to cite this article:}

Pavan Kumar, K., D.K. Swain and Vinay, T.V. 2019. Characterization of Rainfall through Probability Distributions for Yadgir District in Karnataka, India. Int.J.Curr.Microbiol.App.Sci. 8(04): 1099-1113. doi: https://doi.org/10.20546/ijcmas.2019.804.127 